\title{
Vidas de trabajo o sobre cómo reponer la experiencia laboral en una gran ciudad: notas a propósito de la publicación de Queirolo, Graciela Amalia (2018). Mujeres en las oficinas. Trabajo, género y clase en el sector administrativo: Buenos Aires, 1910-1950. Buenos Aires: Biblos.
}

\author{
Silvana A. Palermo \\ Universidad Nacional de General Sarmiento (UNGS), Argentina \\ palermosilvi@gmail.com
}

Escribir hoy un libro sobre el trabajo femenino parecería resultar más demandante que hace un par de décadas, aunque sea, por cierto, igual de fundamental. Existe una literatura que se responsabilizó de sentar interrogantes e interpretaciones pioneras sobre la participación de las mujeres en el mercado de trabajo, sus experiencias en el mundo laboral, sus formas de organización y acción colectiva, sus modos de llevar adelante, sentir y hacer propias una ocupación o actividad laboral en la Argentina del siglo XX. Precisamente, a estas cuestiones se dedica este libro, a partir de un análisis en profundidad de los empleos de escritorio que, tal como bien demuestra, por múltiples y complejas razones con el correr de las décadas quedaron inexorablemente asociados a la feminidad. En consecuencia, al emprender esta empresa, la historiadora Graciela Queirolo afrontó el difícil desafío de contribuir a un campo que, aunque aún en construcción, exhibe ya una notoria fecundidad y ha sido abonado por estudios señeros e influyentes. Puede decirse que su libro está a la altura de las circunstancias y supera con creces las expectativas. En buena medida no sorprende, al tratarse de una obra que resulta de una extensa y laboriosa investigación de posgrado, bajo la dirección de una pionera en este campo -como lo es Mirta Z. Lobato (2007)- y cuya base preliminar -una sólida tesis doctoral- mereció el reconocimiento de la Asociación Latinoamericana e Ibérica de Historia Social (ALIHS).

¿Dónde encontrar las claves del potencial de este libro? Sin duda, sus novedosos hallazgos nacen de haber hecho una inteligente opción temática. Esta investigación descubre los rostros y la vida de ese mundo del trabajo de oficina, señalado como un componente distintivo de esa Buenos Aires devenida metrópolis, el cual permanecía, sin embargo, prácticamente inexplorado. No obstante, puede que no se encuentre aquí su único ni -me atrevería a afirmar- principal mérito. En mi criterio, su mayor contribución radica en los métodos que ensaya para encontrar respuestas renovadas a clásicos interrogantes, las líneas de indagación que inaugura y los cruces historiográficos que plantea. Por todas estas razones, sospecho que este libro será tan bienvenido como fundamental, para quienes se interesan por la historia social de lxs trabajadorxs, las mujeres e inclusive la historia sociocultural urbana.

Trabajo y feminidad, al menos para la Argentina de la primera mitad del siglo XX, deben ante todo reconciliarse, aunque reconozcamos que no es tan sencillo resolver cómo hacerlo. Los dos primeros capítulos de este libro ofrecen un recorrido fecundo al respecto. Ambos se concentran en ponderar el protagonismo de las mujeres en ese mundo del trabajo asalariado urbano. Para ello, Queirolo reconstruye, con todos sus matices y en toda su complejidad, las interpretaciones canónicas de este debate y sus críticos. Como se sabe, la imagen que predominaba a partir de la documentación censal ofrecía una pintura poco auspiciosa para 
quien se dedicaba a la primera mitad del siglo XX, período en el cual, según suponían los estudios pioneros, la participación femenina en el mercado de trabajo se retraía. ${ }^{1}$ De manera pormenorizada, y en sintonía con los estudios que ha venido revisando esta postura clásica,la autora pondera la magnitud de la presencia femenina en los empleos de escritorio y documenta suincremento, a lo largo de ese período, lo que explica que cristalizara la imagen de "la" secretaria, verdadero "ángel de las oficinas".2 Para esto, apela a una revisión crítica de las estadísticas provistas por censos nacionales,el análisis de censos de la ciudad de Buenos Aires y un original escrutinio de los avisos clasificados de losprincipales matutinos del país, que le permite cuestionar la supuesta invisibilidad femenina en el mercadode trabajo y brindar una imagen, panorámica y dinámica a la vez, del protagonismo de las mujeres en lasocupaciones administrativas en esta gran ciudad.

Allí donde el debate podría haberse cerrado, Queirolo encuentra el punto de partida hacia la indagación del problema de las trayectorias laborales, los modos de especialización y promoción ocupacional. ¿Qué requisitos se solicitan para un trabajo de oficina? ¿Qué debe o conviene aprender aquel/aquella que aspira a ejercerlo, a permanecer en él e inclusive a ascender? ¿Dónde y cómo pueden adquirirse esos saberes? Vale subrayar el valor de estas preguntas, a primera vista sencillas, pues ellas no formaron parte del sentido común historiográfico, al menos para las primeras interpretaciones sobre el funcionamiento del mercado de trabajo en las áreas más dinámicas de la Argentina moderna. Como se sabe, tendió a presuponerse que la demanda de trabajo de una economía agroexportadora requería de una débil y escasa especialización, un rasgo al que la oferta, fundamentalmente nutrida por la inmigración ultramarina, se adaptaba bien, por su falta de capacitación y, en última instancia, venía a reforzar. ${ }^{3} \mathrm{Ni}$ el mercado, ni tampoco el pasado contribuían a nutrir el pool de artesanos o trabajadores especializados, al menos en la zona del litoral y la pampa bonaerense, dado el escaso desarrollo de tradiciones artesanales que exhibía el Río de la Plata en comparación con otros lugares de la América Hispana. ${ }^{4}$ En consecuencia, por muchos años, los oficios, las calificaciones, las carreras laborales y profesionales ocuparon un lugar marginal en la agenda de los estudios sobre trabajadores. Y, de hecho, este presupuesto de alta movilidad y baja especialización -que se supone iban de la mano y no hacían más que reforzarse- representa una de las premisas subyacentes en el uso del concepto de sectores populares para aludir a la población trabajadora de la ciudad de Buenos Aires que, como se sabe, propusiera en sus influyentes estudios Luis Alberto Romero. ${ }^{5}$ Precisamente, sobre la base de esta arraigada creencia en las estrategias y elecciones de los sujetos en función de las fluctuaciones, ocasionalidad y dinamismo del mercado laboral, la experiencia del trabajo se remitió a los márgenes a la hora de comprender la conformación de la subjetividad y las identidades colectivas en esa sociedad urbana y, en ocasiones, por extensión al conjunto de la sociedad de la Argentina moderna.

Hace ya varios años, desde perspectivas propias de la historia social y apelando al concepto de género como categoría de análisis, se han realizado estudios monográficos -la vida en ciertas fábricas - pertenecientes a la industria frigorífica, textil, alimenticia-, las comunidades ocupacionales (tipógrafos, marítimos, petroleros, azucareros, ferroviarios, entre otros), las especificidades de determinados sectores o empleos (el doméstico, por ejemplo), la magnitud y relevancia de trabajos femenizados (la enfermería y la docencia), la presencia y las formas del trabajo infantil urbano. Con ello, se ha repuesto la centralidad del trabajo en la cotidianeidad, sociabilidad y cultura popular. Este libro abona este sendero, al priorizar uno de esos empleos característicos de esa modernidad porteña de principios de siglo XX e indagar en detalle quienes los ejercieron, cuáles eran sus calificaciones para realizarlo, cómo se organizaron estas empleadas y empleados para reclamar por condiciones de trabajo más dignas y mejores remuneraciones.

De hecho, tal es el propósito en el que se concentran el tercer y cuarto capítulo de esta obra, al demostrar la relevancia atribuida por estas trabajadoras y trabajadores a sus labores de oficina, por el que tanto invierten en capacitarse o en función del cual se organizan para articular sus reclamos. No es poca la dedicación y esfuerzos que exige aprender esa variada gama de saberes requerida por los trabajos de oficina. En el afán de aprenderlos, perfeccionarse en ellos y adquirir las herramientas que posibiliten el ascenso ocupacional -por más mínimo o inequitativo que fuera- muchas mujeres y hombres dedicaron parte de su juventud y adultez a la capacitación 
laboral en estas lides. En esa esforzada búsqueda, según advierte la autora, parecieron encontrar en el mercado más que en el estado, a su principal aliado. La preponderancia que las Academias Pitman y el incontestable despliegue espacial alcanzado en la Buenos Aires de entreguerras -como bien documenta el anexo de libroevidencia como se retroalimentaron de manera virtuosa la demanda de esos saberes y esa oferta educativa, en la que muchas mujeres y también hombres apostaban a encontrar una oportunidad laboral. Era, según afirma la autora, "una profesionalización breve en tiempos, compatible con otras ocupaciones, a costos accesibles para los niveles salariales de las clases trabajadoras" (Queirolo, 2018, p. 238).

De este modo, esta obra esboza líneas de indagación, sumamente sugerentes, sobre la relación entre trabajo y educación. A partir de este caso de estudio, se vislumbra la centralidad de ciertas instituciones o empresas - y de determinadas propuestas y estrategias de capacitación- a los que quizás se les ha prestado insuficiente atención y que merecerían, a la luz de estos hallazgos, investigaciones en sí mismas: academias de dactilografía, taquigrafía, idiomas - puede imaginarse también de enfermería, corte y confección, peluquería, plomería, electricidad- y toda una multiplicidad de "oficios" aprendidos por libros y cursos por correspondencia (para mujeres y hombres), en escuelas nocturnas, en instituciones barriales, religiosos, centros educativos públicos o privados. Al dotarlas de relevancia, en función de las necesidades de esa población trabajadora que confía en adquirir allí las capacidades que su empleo le demanda, este estudio toma distancia de la conceptualización de ese aprendizaje como "saberes del pobre" y recupera su centralidad y sentidos en la realización de una carrera laboral. Así, invita a pensar en la especialización y capacitación, en profesiones y “oficios” del siglo XX, estos últimos nacidos ya de la modernidad industrial, las innovaciones tecnológicas, la producción y el consumo de masas.

Que la experiencia laboral de estas mujeres y hombres, empleadxs en tareas de escritorio adquiere centralidad a la hora de pensarse como individuos y como actores sociales, también lo documenta muy convincentemente el cuarto capítulo, dedicado a las Federaciones de Empleados de Comercio (FEC) y Federación de Asociaciones Católicas de Empleadas (FACE). De hecho, ambas entidades gozaron de una creciente capacidad de convocatoria a medida que avanza el siglo XX. Secretarias, dactilógrafas, taquígrafas y toda la variedad de lxs empleadxs de escritorio devinieron objeto de objeto de atención y también disputa entre las izquierdas, en particular el socialismo, que primó en la conducción de la FEC, y el catolicismo social, inspirador de la FACE. En ese clima de polarización ideológica, ambas apostaron a la movilización y la participación colectiva, lo que explica la presencia de mujeres protestando o celebrando en las calles porteñas tras pancartas de ambas agrupaciones. En tal sentido, estas instituciones les abrieron posibilidades en términos de experiencia organizativa y de articulación de reivindicaciones propias. No obstante, también definieron evidentes limitaciones. En ambas, las mujeres desempeñaron un papel subordinado, y tanto la FEC como la FACE concibieron el trabajo de sus afiliadas como una circunstancia transitoria, que no hizo más que reforzar la ideología de la domesticidad y la identificación de la mujer como madre y cuidadora del hogar, más que favorecer su despliegue como militante o facilitar la formulación de sus derechos en tanto trabajadora.

De manera original, el último capítulo del libro se concentra en la relevancia del trabajo de oficina, en especial el realizado por las empleadas de escritorio, a partir de lo mucho que se dice sobre ellas en la literatura, en general, y en las revistas de circulación masiva, en particular. El análisis descubre dos estereotipos antagónicos sobre la empleada de escritorio: "el hada del teclado" y la "empleada oprimida", centrado uno sobre la supuesta banalidad de la vida de la empleada y su protagonismo en tanto consumidora y, el otro, enfocado en la experiencia de explotación y los constreñimientos materiales que las forzaban a proletarizarse. Pese a sus diferencias, ambas representaciones dotan de sentido a aquello que la autora ha llamado, inspirada en la interpretación de Joan Scott (2012) respecto al feminismo occidental, "la paradoja de la empleada". Esto es, una conceptualización que reúne dos condiciones aparentemente irreconciliables: por un lado, el reconocimiento de los beneficios de la participación asalariada (en las posibilidades de consumo relativamente autónomo y el logro de cierto estatus), por el otro, la dimensión opresiva propia del trabajo asalariado. En esa paradoja, argumenta Queirolo, ambas conceptualizaciones coinciden en 
concebir "la participación femenina asalariada como excepcional y, por ende, legitimaron las prácticas de inequidad" (Queirolo, 2018, p. 235).

Al indagar esa "paradoja de la empleada" en sus múltiples aristas, al contemplarlas en la cotidianeidad laboral y en el consumo, en las organizaciones colectivas y en las viñetas y aguafuertes porteñas, la autora devuelve a estas mujeres su condición de asalariadas a la vez que las formas que las distinguen, los consumos materiales y simbólicos que las jerarquizan, pero también las experiencias que las asemejan a los obreros y las obreras fabriles, en teoría típicos exponentes de la clase trabajadora. De esta manera, apelando al concepto de género como categoría de análisis, interviene en el debate en torno a la construcción de las clases medias en la Buenos Aires de entreguerras y apuesta por una interpretación que privilegia la experiencia asalariada, como fundante de la construcción identitaria de esta población trabajadora.

Ese último capítulo representa un excelente cierre para un libro en el cual los empleos de escritorio y quienes los protagonizan son sometidos a un intenso escrutinio. Es aquí donde se advierte de manera más clara el heterogéneo y vasto corpus documental en el que se basa esta investigación. En tal sentido, resulta una fuente de inspiración para quienes se interesan por la historia sociocultural del trabajo al ofrecer pistas sobre cómo interrogar y analizar una documentación no siempre prioritaria en los estudios sobre trabajadores como lo son las revistas de circulación masiva, la literatura, el folletín, las viñetas o letras de tango, los productos de la industria cultural para decirlo en términos más amplios. Y tal como lo advierte la autora, ellas parecen ser una cantera fecunda. Allí se habla de los trabajadores y, fundamentalmente, de las mujeres trabajadoras, se construyen y difunden estereotipos sobre su labor, se las interpela en tanto consumidoras y trabajadoras. Como sostiene Queirolo, en esos semanarios y revistas de circulación masiva, las empleadas de escritorio son prácticamente omnipresentes, casi un símbolo de la modernidad misma, tan relevante como los grandes edificios, mundos de negocios o la grilla de la urbe, por los que pasan sus días y transitan.

Este es un libro que repone el trabajo de las mujeres en la gran ciudad, como lo sintetiza sin ambages su título. Al leerlo, recordé aquello que sostenía Ann Farnsworth-Alvear (2000) en su estudio sobre las obreras en la industria textil de Medellín, Colombia, también en las primeras décadas del siglo XX. Una vez que se descubre que las mujeres protagonizan ese mundo, los interrogantes no hacen sino multiplicarse: ¿por qué y cómo están allí? ¿Qué estructuras posibilitan su participación? ¿Cuál es el peso explicativo que le atribuimos a la agencia de las propias mujeres y de otros actores sociales? ¿Qué significaron esas prácticas y experiencias para ellas y para la sociedad? Mujeres en las oficinas explora precisamente todas cuestiones. Y, al reponer su protagonismo, Queirolo logra explicar su agencia y subalternidad a la vez, esa combinación de empoderamiento femenino y desigualdad tan persistente y penetrante. Así aprendemos que, entre 1910 a 1950, una mujer podía acceder a un trabajo de escritorio, e inclusive llevar adelante una carrera laboral. No obstante, no podía escapar al dilema del llamado piso pegajoso y techo de cristal. Como sostiene la autora, la inequidad laboral se hizo presente debido a la irreductible brecha salarial -a igual trabajo las mujeres recibieron una remuneración menor-, la segregación horizontal -esto es, ocuparon aquellos cargos de menor retribución-, y la segregación vertical, es decir sus carreras laborales nunca alcanzaron metas tan ventajosas como las de sus pares de traje y corbata.

La publicación de este libro, cuya solvencia empírica y despliegue interpretativo no se alcanzan en detrimento de la fluidez y el buen estilo narrativo, merece celebrarse. Es una obra oportuna y necesaria para el campo de la historia social del trabajo y la historia de las mujeres en América Latina, un libro también rico y sugerente para quienes se interesan por la sociabilidad y cultura popular urbana. Desde hace un par de décadas, los pronósticos respecto a la historia social se han mostrado pesimistas. Una y otra vez en los balances publicados en las revistas especializadas se diagnosticaba la crisis de la historia social y se insistía en que aquellas problemáticas en torno al mercado de trabajo, el mundo del trabajo, sus experiencias y representaciones, los debates en torno al concepto de clase no suscitaban la curiosidad de los/las jóvenes investigadores. En este clima académico más que desafiante esta investigación sobre historia del trabajo, las mujeres y la modernidad urbana, encuentra una historiadora tan sensible como esforzada, increíblemente 
tesonera en desplegar lo mejor del arte del oficio para demostrar que la historia de las trabajadoras de oficina, los "empleos de escritorio", merecían una investigación en profundidad y pueden, a la vez, brindar pistas para ampliar nuestros horizontes teóricos, metodológicos y estimularnos a afianzar diálogos historiográficos fecundos.

\section{ReFERENCIAS}

Farnsworth-Alvear, A. (2000). Dulcinea in the Factory. Myth, Morals, Men and Women in Colombia's Industrial Experiment, 1905-1960. Duke: Duke University Press.

Feijoo, M. del C. (1990). Las trabajadoras porteñas a comienzos del siglo XX. En Armus, D. (Ed.), Mundo urbano y cultura popular. Estudios de Historia Social Argentina. Buenos Aires: Sudamericana.

Gutiérrez, L. H. \& Romero, L. A. (1995). Sectores populares, cultura y política. Buenos Aires en la entreguerra. Buenos Aires: Sudamericana.

Lobato, M. Z. (2007). Historia de las trabajadoras en la Argentina (1869-1960). Buenos Aires: Edhasa.

Queirolo, G. (2006). Mujeres que trabajan: una revisión historiográfica del trabajo femenino en la ciudad de Buenos Aires (1890-1940). Nuevo Topo. Revista de historia y pensamiento crítico, 3, 29-49. Recuperado de https://nue votopo.wordpress.com/nuevo-topo-no3/

Recchini de Lattes, Z. R. \& Wainermann, C. (1977). Empleo femenino y desarrollo económico, algunas evidencias. Desarrollo Económico, 17(66), 301-317.

Rocchi, F. (2000). Concentración de capital, concentración de mujeres. Industria y trabajo femenino en Buenos Aires. En Gil Lozano, F; Pita, Vy Ini, G. (Eds.), Historia de las mujeres en la Argentina. Tomo II (pp. 222-243). Buenos Aires: Taurus.

Sábato, H. y Romero, L. A. (1992). Los trabajadores de Buenos Aires. La experiencia del mercado: 1850-1880. Buenos Aires: Sudamericana.

Scott, J. W. (2012). Las mujeres y los derechos del hombre: Feminismo y sufragio en Francia, 1789-1944. Buenos Aires: Siglo Veintiuno Editores.

\section{Notas}

1. Respecto a los principales estudios que asociaron ese retraimiento de la participación femenina en el mercado de trabajo al despegue económico de la Argentina, véase de Lattes y Wainermann (1977) y subsecuentes publicaciones de ambas autoras. Sobre la sobreestimación de la presencia femenina en el trabajo fabril, ver Feijoo (1990).

2. Entre quienes iniciaron una revisión en torno a la participación laboral de las mujeres en el período 1880-1914cf. Lobato (2007) y Rocchi (2000). Para más detalle al respecto, ver Queirolo (2006).

3. Roberto Cortés Conde (1979) sistematizó esta interpretación sobre el funcionamiento del mercado de trabajo y los desplazamientos de la oferta y la demanda.

4. Por otra parte, según Hilda Sábato y Luis Alberto Romero, “el afincamiento en un oficio podía ser igualmente contraproducente si lo que se buscaba era atrapar la oportunidad. (...) Si la incertidumbre laboral tenía como contrapartida la oportunidad, la búsqueda de ésta requería de pocas raíces laborales y mucha flexibilidad. Cuanto más compenetrado estuviera el trabajador con su oficio, más difícil le resultaba correr tras de la oportunidad. Cuanto más corría tras de la oportunidad, menos firmes eran sus raíces laborales." (Sábato y Romero, 1992, p. 258).

5. "El rasgo más notable de la sociedad de Buenos Aires -sostiene Romero en su reconocido estudio elaborado junto a Leandro H. Gutiérrez- la fuerte movilidad y la expectativa generada por ella, más fuerte aún, conspiró contra la constitución de identidades de clase firmes y consistentes." Y asimismo se advierte "en este contexto se constituyó una nueva identidad de los sectores populares. Fue más popular que trabajadora, pues no se centró en el trabajo sino en "las ocho horas para lo que queramos', que seguían a aquel, y que en buena medida transcurrían en el barrio." (Gutiérrez y Romero, 1995, p. 15 y 13). La cursiva es propia. 